TENDENCIAS

Revista de la Facultad de Ciencias

Económicas y Administrativas.

Universidad de Nariño

ISSN 0124-8693 ISSN-E 2539-0554

Vol. XIX No. 2 - 2० Semestre 2018

Julio - Diciembre - Páginas 113-137

\title{
HACIA LA GESTIÓN Y SANEAMIENTO FINANCIERO Y FISCAL DE LOS MUNICIPIOS DEL DEPARTAMENTO DE ANTIOQUIA ${ }^{1 *}$
}

\author{
TOWARDS THE MANAGEMENT AND FINANCIAL AND FISCAL \\ SANITATION OF THE MUNICIPALITIES OF THE DEPARTMENT OF \\ ANTIOQUIA
}

\section{PARA A GESTÃO E SANEAMENTO FINANCEIRO E FISCAL DOS MUNICÍPIOS DO DEPARTAMENTO DE ANTIOQUIA}

\section{URREGO ESTRADA_Gleidy Alexandra, GUTIÉRREZ OSSA_Jahir Alexander}

Candidata a doctora en Ciencias Humanas y Sociales. Magíster en Hábitat. Universidad Nacional de Colombia, Sede Medellín. Investigadora Facultad de Administración. Universidad CES. E-mail: gleidy.urrego@gmail.com, Colombia.

PhD en Administración Pública, Atlantic International University (AIU), Honolulú, USA. Docente e investigador Facultad de Administración. Universidad CES. E-mail: jagogutierrez@ gmail.com, Colombia.

Recibido: 15 de abril de 2018 Aprobación definitiva: 10 de noviembre de 2018

\section{DOI: http://dx.doi.org/10.22267/rtend.181902.100}

\section{RESUMEN}

A partir de la Constitución Política de 1991, la administración de los recursos financieros en Colombia es objetivo central de la descentralización fiscal, en tanto, la planificación y ejecución financiera está enfocada en la eficiencia, eficacia y resultado, a fin de consolidar capacidades gerenciales a escala departamental y municipal de sostenibilidad fiscal. El presente escrito tiene como objetivo aproximarse al análisis cualitativo de la capacidad de recaudo (ingresos), condiciones de fiscalidad (Impuestos) y la consolidación de una estructura financiera (saneamiento), que permita mantener la relación de

$1^{*}$ Este artículo es producto de la línea de investigación: Estrategia, Dirección y Reputación Corporativa. Grupo de investigación en Gestión Empresarial. Universidad CES. 2018 
equilibrio entre la deuda, los gastos y el presupuesto de los municipios del departamento de Antioquia. La estrategia metodológica es de tipo cualitativa, con un método el deductivo, a partir de dos fases: i) revisión bibliográfica de fuentes normativas como Ley 1551 de 2012 (Condición Económica) en conjunto con la Ley 1454 (Ordenamiento) de 2011 y ii) análisis de contenido de las mismas. Como conclusiones principales: el bagaje constitucional del 91 no fue claro en materia de generación de impuestos territoriales. Se está en mora de comprender la eficacia territorial de la legislación fiscal y financiera, requerida, para que pueda establecerse una estructura eficiente de desempeño financiero y fiscal que permite cumplir cometido constitucional expreso en el artículo 311.

Palabras clave: gestión financiera, gestión fiscal, saneamiento financiero municipal.

JEL: H0, H1, H11

\section{ABSTRACT}

Since the Political Constitution of 1991, the administration of financial resources in Colombia is a central objective of fiscal decentralization, while financial planning and execution is focused on efficiency, effectiveness and results, to consolidate managerial capacities to departmental and municipal scale of fiscal sustainability. The present document aims to approach the qualitative analysis of the collection capacity (income), taxation conditions (Taxes) and the consolidation of a financial structure (sanitation), which allows to maintain the equilibrium relationship between debt, expenses and the budget of the municipalities of the department of Antioquia. The methodological strategy is qualitative, with a deductive method, based on two phases: i) bibliographic review of normative sources such as Law 1551 of 2012 (Economic Condition) in conjunction with Law 1454 (Ordinance) of 2011 and ii) Content analysis of the same. As main conclusions: the constitutional baggage of 91 was not clear regarding the generation of territorial taxes. It is in default to understand the territorial effectiveness of the fiscal and financial legislation, required, so that an efficient structure of financial and fiscal performance can be established that allows fulfilling constitutional commitment expressed in article 311.

Keywords: Financial management, fiscal management, municipal financial sanitation.

JEL: H0, H1, H11 


\section{RESUMO}

A partir da Constituição de 1991, a gestão de recursos financeiros no objectivo central da Colômbia de descentralização, entretanto, o planejamento financeiro fiscal e implementação está focada em eficiência, eficácia e os resultados, para consolidar as capacidades de gestão escala departamental e municipal de sustentabilidade fiscal. O presente trabalho tem como objetivo abordar a análise qualitativa da capacidade de coleta (de renda), as condições de tributação (impostos) e a consolidação da estrutura financeira (saneamento), que irá manter a relação de equilíbrio entre a dívida, despesas e o orçamento dos municípios do departamento de Antioquia. A abordagem metodológica é do tipo qualitativa, com um método dedutivo a partir de duas fases: i) revisão da literatura das fontes do direito como a Lei 1.551 de 2012 (Estatuto Económica), juntamente com a Lei 1454 (Portaria) de 2011 e ii) Análise de conteúdo do mesmo. Como principais conclusões: a bagagem constitucional de 91 não foi clara quanto à geração de impostos territoriais. É atrasado para compreender a eficácia territorial da legislação fiscal e financeira, necessária para uma eficiente estrutura de desempenho financeiro e fiscal que permite a conformidade comprometida expressar artigo constitucional 311 pode ser estabelecida.

Palavras-chave: gestão financeira, gestão fiscal, a reestruturação financeira municipal.

JEL: H0, H1, H11

\section{INTRODUCCIÓN}

La guía trazada por el Estado tiende a endurecer aún más los lineamientos en materia de administración de recursos, gestión pública territorial y sostenibilidad fiscal a escala departamental y municipal. Mientras tanto, los entes territoriales ${ }^{2}$ particularmente municipales, continúan respondiendo en la medida de las circunstancias, a pesar que los requerimientos plantean compromisos más contundentes con respecto a la recuperación de la gobernabilidad territorial a través del mejoramiento fiscal, presupuestal y de saneamiento. En consecuencia,

2 Los entes territoriales son unidades político-administrativas que hacen parte de la estructura del estado colombiano, señalado en la Constitución Política de 1991, en el artículo 286: Son entidades territoriales los departamentos, los distritos, los municipios y los territorios indígenas. 
los municipios deben evaluar las capacidades y condiciones que tienen con respecto a dichas exigencias, en reparo o no de reconvertir su estructura territorial.

El presupuesto municipal tiene tres funciones básicas: a) Proyectar los ingresos y rentas a percibir durante la vigencia fiscal y autorizar los respectivos gastos e inversiones; b) Cumplir con una porción, atendiendo criterios de prioridad, de los programas y proyectos contenidos en el Plan de Desarrollo, c) Alcanzar objetivos financieros, que no son otra cosa que adecuar el comportamiento real de los ingresos a las proyecciones contenidas en el Plan de Desarrollo. (Herrera,2003, pág. 24).

El departamento de Antioquia sería el ente regional que más municipios perdería de no considerarse con aplomo y fortaleza lo que implica la revisión endógena e interna de lo que implica acoger la normatividad prescrita para el efecto. En primer lugar, considerando en estricto sentido a los municipios que definitivamente no son capaces de sopesar las exigencias de la ley, y que para el efecto puedan contemplar la reconversión territorial que establece la ley de ordenamiento territorial (Ley 1454 de 2011). En segundo, no pueden superar su condición económica (Ley 1551 de 2012), normas paralelas que plantean la conformación de otras formas territoriales, estimadas también en ley, y de paso aprovisionar los criterios en materia presupuestal para apoyar a los que pueden mejorar.

El departamento de Antioquia presente las cualidades necesarias para ser tomado como caso de estudio. La cantidad de municipios que están al borde del precipicio fiscal en cuanto a ingresos y gastos, por ende, del presupuesto, implica que sea este quien abandere la revisión de los elementos que componen el marco jurídico que recrea una nueva forma de entender el territorio, en donde ya no solo prima el ordenamiento como marco de referencia para solventar las necesidades municipales puntuales. La condición económica pasa a refrendar la capacidad de gestión que tienen los entes territoriales para salir avante de un marco jurídico que no atiende condiciones particulares, pero que, si explica los requerimientos o salvedades sobre las cuales podría atenderse la situación de los municipios.

La idea estriba en acoger primero los lineamientos en materia de ordenamiento territorial y luego involucrarlos con respecto al nuevo régimen municipal para finalmente poder establecer las bondades de acoger una medida de ajuste supra 
territorial que puede mejorar las condiciones de municipios que en definitiva no tienen salida por cuenta propia. Seguidamente mostrar la posibilidad de apostar a municipios que además de salvar su categoría podrían mejorar con el tiempo si se atiende desde la óptica de la gestión pública la prioridad de internalizar la reestructuración administrativa, contable y financiera como un acuerdo y política reinante en las administraciones municipales dispuestas a recuperar la gobernabilidad.

La estructura del articulo obedece a la siguiente composición: 1. Una revisión del andamiaje constitucional en cuanto a las perspectivas que se tienen en materia de generación de impuestos por parte de los entes territoriales. 2. Una evaluación sobre la estructura institucional y marco legal de cara a la programación del saneamiento fiscal municipal, y 3. La posible estructuración que en materia de programación financiera y fiscal podría orientar al programa de saneamiento municipal del Departamento de Antioquia. Es conveniente, que se inicie un proceso permanente de trabajo en este campo por cuenta de la Secretaria de Hacienda Departamental y de lleno a escala gubernamental.

\section{Metodología}

Como abordaje metodológico la investigación es de tipo cualitativa, con un método el deductivo que da cuenta de la gestión y saneamiento financiero y fiscal de los municipios del departamento de Antioquia, a partir de dos fases: i) revisión bibliográfica de las principales normas (véase cuadro 1) que ha puesto la consecución de dichos temas a cargo de gobernaciones y municipios de Antioquia y ii) análisis de contenido de estas fuentes en relación con categorías de análisis como: generación de recursos, finanzas públicas y saneamiento fiscal.

\section{Cuadro 1}

Normograma

\begin{tabular}{|c|l|l|}
\hline Norma & \multicolumn{1}{|c|}{ Fecha } & \multicolumn{1}{c|}{ Propósito } \\
\hline $\begin{array}{c}\text { Ley } \\
1551\end{array}$ & $\begin{array}{l}\text { Julio } 6 \text { de } \\
2012\end{array}$ & $\begin{array}{l}\text { Por la cual se dictan normas para modernizar la organización y el } \\
\text { funcionamiento de los municipios. }\end{array}$ \\
\hline $\begin{array}{c}\text { Ley } \\
1454\end{array}$ & $\begin{array}{l}\text { Junio 28 } 28 \\
\text { de } 2011\end{array}$ & $\begin{array}{l}\text { Por la cual se dictan normas orgánicas sobre ordenamiento territorial y } \\
\text { se modifican otras disposiciones. }\end{array}$ \\
\hline
\end{tabular}


Hacia la gestión y saneamiento financiero y fiscal de los municipios del departamento de Antioquia Urrego Estrada_Gleidy Alexandra, Gutiérrez Ossa_Jahir Alexander

\begin{tabular}{|c|l|l|}
\hline $\begin{array}{c}\text { Ley } \\
1450\end{array}$ & $\begin{array}{l}\text { Junio 16 } \\
\text { de } 2011\end{array}$ & Por la cual se expide el Plan Nacional de Desarrollo, 2010-2014. \\
\hline $\begin{array}{c}\text { Ley } \\
1150\end{array}$ & $\begin{array}{l}\text { Julio 16 de } \\
2007\end{array}$ & $\begin{array}{l}\text { Por medio de la cual se introducen medidas para la eficiencia y la } \\
\text { transparencia en la Ley } 80 \text { de 1993 y se dictan otras disposiciones } \\
\text { generales sobre la contratación con Recursos Públicos. }\end{array}$ \\
\hline $\begin{array}{c}\text { Ley } \\
819\end{array}$ & $\begin{array}{l}\text { Julio 9 de } \\
2003\end{array}$ & $\begin{array}{l}\text { Por la cual se dictan normas orgánicas en materia de presupuesto, } \\
\text { responsabilidad y transparencia fiscal y se dictan otras disposiciones }\end{array}$ \\
\hline $\begin{array}{l}\text { Ley } \\
715\end{array}$ & $\begin{array}{l}\text { Diciembre } \\
21 \text { de 2001 }\end{array}$ & $\begin{array}{l}\text { Por la cual se dictan normas orgánicas en materia de recursos y } \\
\text { competencias de conformidad con los artículos 151, 288, 356 y 357 } \\
\text { (Acto Legislativo 01 de 2001) de la Constitución Política y se dictan } \\
\text { otras disposiciones para organizar la prestación de los servicios de } \\
\text { educación y salud, entre otros. }\end{array}$ \\
\hline $\begin{array}{l}\text { Ley } \\
617\end{array}$ & $\begin{array}{l}\text { Octubre } \\
\text { de 2000 }\end{array}$ & $\begin{array}{l}\text { Por la cual se reforma parcialmente la Ley 136 de 1994, el Decreto } \\
\text { Extraordinario 1222 de 1986, se adiciona la Ley Orgánica de } \\
\text { Presupuesto, el Decreto 1421 de 1993, se dictan otras normas } \\
\text { tendientes a fortalecer la descentralización, y se dictan normas para la } \\
\text { racionalización del gasto público nación. }\end{array}$ \\
\hline $\begin{array}{l}\text { Ley } \\
358\end{array}$ & $\begin{array}{l}\text { Enero 30 } \\
\text { de 1997 }\end{array}$ & $\begin{array}{l}\text { Por la cual se reglamenta el artículo 364 de la Constitución y se } \\
\text { dictan otras disposiciones en materia de endeudamiento. Modificada } \\
\text { por la Ley 795 de 2003 (15 de enero): Por la cual se ajustan algunas } \\
\text { normas del Estatuto Orgánico del Sistema Financiero y se dictan otras } \\
\text { disposiciones. }\end{array}$ \\
\hline
\end{tabular}

Fuente: Elaborada propia.

\section{Resultados}

\section{Estructura constitucional de la generación de recursos de los entes territoriales en Colombia}

La Constitución colombiana de 1991 establece claramente el tipo de acompañamiento que debe dar el Estado con respecto al crecimiento y desarrollo de los departamentos y municipios. Ajustes que condujeron para que se presentaran dificultades en cuanto al manejo de recursos y la consecución de lo consagrado, hecho que produjo la actual situación de crisis de las finanzas territoriales frente a los planteamientos proferidos por el Estado a saber. Al respecto, el Estado comenzó a desembolsar una importante cuantía de recursos para que los entes respondieran a las tareas encomendadas con respecto a educación, salud, servicios públicos e infraestructura, precepto que implico reajustes en la estructura de la administración pública territorial: 
La financiación del desarrollo territorial está determinada por el modelo de descentralización vigente en el país. En efecto, con base en la definición de Colombia como un Estado unitario, organizado en forma descentralizada y con autonomía de sus entidades territoriales, se ha estructurado un esquema tributario para fortalecer los ingresos propios y propiciar la redistribución entre entidades territoriales, se ha diseñado un esquema de transferencias intergubernamentales y se han expedido normas para el acceso al crédito. (Dirección de Desarrollo Territorial Sostenible, 2009, pág. 6).

El incremento de los gastos centrales terminó sobrepasado por los gastos de los entes territoriales, que con cargo a los empréstitos y encargos fiduciarios de recursos en compañía con el Estado central tomaron los recursos disponibles para la descentralización; base para auspiciar una serie de desembolsos que no serían compensados por obras o la superación de las necesidades registradas en cada departamento y municipio del país. En consecuencia, el amplio margen de gastos y la baja estructura fiscal presentada por los entes territoriales, deterioro además de las finanzas regionales, la capacidad del Estado para continuar financiando el esfuerzo que representaba para el efecto, entregar una estructura financiera descentralizada que, bajo expectativa, se esperaba que contribuyera al mejoramiento de las condiciones locales.

En teoría, la aplicación del modelo de descentralización fiscal implica tomar una de dos decisiones1: en la primera, los gobiernos subnacionales legislan y recaudan autónomamente los impuestos necesarios para la financiación de sus competencias, mientras que, en la segunda, el gobierno central legisla y recauda la mayor parte de los impuestos, para luego distribuir un alto porcentaje a los gobiernos subnacionales, mediante un sistema de transferencias que compense las diferencias en capacidad fiscal2(Bonet), estimule el esfuerzo fiscal y logre cabalmente la financiación de los bienes y servicios a cargo del estado. La decisión que se tome, configurará el grado de concentración de las responsabilidades de ingreso y de gasto en los niveles de gobierno y a su vez, determinará el nivel de competencias que deba asumir cada nivel de gobierno, las cuales deberán ser capaces de ser financiadas con el esquema fiscal adoptado. (Dirección de Desarrollo Territorial Sostenible, 2005 pág. 9).

La poca estructura fiscal de los entes territoriales y las magras condiciones del Estado para proseguir con sus obligaciones, insto para que este se acogiera a un acuerdo de pagos con la banca multilateral que, por primera vez, haría pública la incapacidad del Estado para responder ante la deuda internacional, escenario 
que termino con acuerdo de ajuste fiscal y presupuestal con facilidad ampliada con el Fondo Monetario Internacional en 1998. Esta revisión a la estructura financiera, fiscal y de gastos respecto a la generación de ingresos y desembolso de recursos, sirvió para que se formularan una serie de ajustes con marco de ley, sobre las cuales hoy se extiende a los entes territoriales la necesidad de ajustar las arcas públicas no solo para evitar crisis, sino para recuperar las condiciones de estabilidad financiera del Estado en general.

La descentralización se propuso como objetivo la autonomía fiscal de los municipios. Los resultados fiscales de los municipios estudiados en este trabajo muestran por el contrario una peor situación fiscal. No obstante, el alto ritmo de crecimiento de las transferencias a los gobiernos locales estudiados para cerca del 53\% de ellos, su situación fiscal empeoró en los años noventa. Sólo se encontró que un $10 \%$ de los municipios de la muestra estudiada, registra mejores indicadores fiscales y financieros que a comienzos de la década. Lo anterior se corrobora porque a lo largo de los años noventa, los municipios generaron muy rápidamente desahorro corriente. Este resultado se explica más por el gran incremento del gasto que por el comportamiento de los ingresos tributarios, los cuales aumentaron sostenidamente entre 1998-1999. Se encontró igualmente que hay aumentos del gasto derivado del sistema automático de transferencias, lo que ratifica que el efecto "fly-papper" ocurre por efecto del diseño de la descentralización. (Zapata et., al, 2001, pág. 69).

El entramado legislativo al paso de cada requerimiento proveería los fundamentales jurídicos para que en el país se repensara la idea sobre el equilibrio fiscal y el saneamiento financiero y presupuestal con respecto a la relación de ingresos, obligaciones y los desembolsos de recursos en general. La revisión del papel del Estado en la economía en virtud de sus compromisos y tareas a la par con la definición de programas de privatización, sólo sería el punto de partida para que a todos los entes territoriales respondieran con cargo a su estructura a cada criterio fundamentado. Ajustes a la administración pública territorial, la revisión del paquete de recursos por transferencias y el reajuste a los gastos, serían solo los pasos para establecer todo el paquete de medidas que traería el buscar el equilibrio fiscal y presupuestal central y territorial.

La ejecución de las recetas proferidas por el Fondo Monetario Internacional estableció una serie de medidas que terminaron internalizadas en los estamentos centrales, descentralizados y públicos del Estado. Así, la aparición de figuras 
como las categorías departamental y municipal, y con ella, la ganancia o pérdida de la misma por cuenta de los acertados o malos manejados de los recursos públicos, sería el abrebocas de una serie de criterios mucho más contundentes para que en los entes territoriales se auspiciará el escenario de la búsqueda de recursos o buen manejo de los poseídos, so pena de que perdieran la categoría definida por el Estado (DNP). En su defecto pasaran a ser intervenidos por los diferentes entes de control y de planeación, previsto en la Ley 358 de 1997, modificada por la Ley 795 de $2003^{3}$ frente a la relación ingresos y gastos con respecto a los indicadores y señales arrojados a partir de la información financiera de cada ente territorial.

El ajuste implementado a través de las propuestas del organismo internacional fundamentaría el quehacer de los entes territoriales, en cuanto al manejo de los recursos producto del sistema general de participación, otrora situado fiscal, a su vez la revisión con cargo al manejo de las regalías y las transferencias se ajustarían conforme a las necesidades territoriales y el volumen de población. Así mismo, los entes tendrían la obligación de revisar la estructura pública de los respectivos estamentos con el propósito de ajustarse conforme a su categorización municipal, de conformidad con la Ley 617 de $2000^{4}$. De paso, entraron con más

3 1) Modificada por la Ley 1328 de 2009, publicada en el Diario Oficial No 47.411 de 15 de julio de 2009, 'Por la cual se dictan normas en materia financiera, de seguros, del mercado de valores y otras disposiciones'; 2) Modificada por la Ley 1151 de 2007, publicada en el Diario Oficial No. 46.700 de 25 de julio de 2007, 'Por la cual se expide el Plan Nacional de Desarrollo 2006-2010'; 3) Para la interpretación de esta Ley debe tenerse en cuenta que fue expedido el Decreto 4327 de 2005, spor el cual se fusiona la Superintendencia Bancaria de Colombia en la Superintendencia de Valores y se modifica su estructura), publicado en el Diario Oficial No. 46.104 de 26 de noviembre de 2005; 4)Mediante el Decreto 4365 de 2004, publicado en el Diario Oficial 45.774 de 27 de diciembre de 2004, «se liquida el Presupuesto General de la Nación para la vigencia fiscal de 2005, se detallan las apropiaciones y se clasifican y definen los gastos〉; 5) Modificada por la Ley 921 de 2004, publicada en el Diario Oficial 45.774 de 27 de diciembre de 2004, «Por la cual se decreta el Presupuesto de rentas y recursos de capital y Ley de apropiaciones para la vigencia fiscal del 1 o de enero al 31 de diciembre de 2005'

4 A partir de la implementación de normatividad como las leyes 358 del 97 y la ley 617 de 2000, ley 550 del 999, 715 de 2001 y entre otras, la territorialidad colombiana tanto local como central, han logrado superar paulatinamente las dificultades financieras referentes al desequilibrio entre ingresos y egresos, lo que en su momento puso en tela de juicio su viabilidad fiscal en el mediano y largo plazo. Reorientación de las rentas, limitación del gasto, reestructuración de la deuda, regulación del crédito, han permitido corregir los desequilibrios estructurales en materia fiscal. Cuáles son los elementos sustanciales desde la relación Ingresos/ Gastos, que permiten garantizar la sostenibilidad en el LP del superávit fiscal de la territorialidad, antes y después del año 2000 (punto de quiebre en la tendencia). (Zuluaga, C. s.f). 
fuerza, criterios vinculados con la implementación de Normas y Técnicas para el Control y la Gestión Pública (NTCGP-1000-2001), a la par con mecanismos de control interno (MECI-2000), y la legislación en materia de responsabilidad fiscal (Ley 819 de 2003).

La contratación también pasaría a revisión al reformularse la Ley 80 de 1993, que traería la aparición de la Ley 850 de 2003 en materia de participación ciudadana, control y participación ciudadana, y la Ley 1150 de 2007 sobre contratación pública y la Ley 1551 de 2012 sobre ajustes a la administración pública. A su vez que el ajuste a la Ley 550 de 1999, en materia de intervención económica y reestructuración de los entes territoriales para asegurar la función social de las empresas y lograr el desarrollo armónico de las regiones, y de quiebra con la Ley 1116 de 2006, a fin de establecer el Régimen de Insolvencia Empresarial. En dicha dirección, fueron aprobados la Ley 1450 de 2011 del plan de desarrollo, que daría paso a la Ley 1448 de restitución de tierras de 2011, la Ley 1454 de 2011 sobre ordenamiento territorial, la Ley 1508 de 2012 sobre Alianzas Publico Privada y la Ley 1551 de 2012, que implicarían la disposición y reglamentación de la administración pública en todo el país.

En el último decenio el país ha avanzado en un proceso de modernización de la administración pública, de reforma y fortalecimiento de las instituciones presupuestales y de las herramientas para mejorar la gestión pública (Ley de Responsabilidad y Transparencia Fiscal, sistemas de monitoreo del gasto, de evaluación de resultados, fortalecimiento de mecanismos de rendición de cuentas, introducción de nuevos clasificadores de gasto, acordes con estándares internacionales, Marco Fiscal de Mediano Plazo, MFMP, Marco de Gasto de Mediano Plazo, MGMP, etc.), todo lo cual ha contribuido a mejorar los procesos de programación, asignación, ejecución, evaluación, seguimiento y control del gasto público y de rendición de cuentas, y ha favorecido la transparencia fiscal. (Ministerio de Hacienda y Crédito Público, 2011, pág. 23).

El repunte de las contingencias, demandas y problemáticas que de manera directa o eventualmente rebasan en muchos de los municipios las posibilidades económicas para que estos puedan solventar con crecer las obligaciones y responsabilidades que representan el cumulo de actividades y funciones que deben procurar. De allí que, el Gobierno Nacional haya asumido con carácter de urgencia la Defensa Jurídica y Patrimonial del Estado que claramente pone limite 
a las demandas y requerimientos que conforme a distintos cargos se ha venido haciendo a las diferentes formas de gobierno e instituciones representantes de estos. Para ello, ha planteado a través de la ley las condiciones sobre las cuales debe realizarse la contratación pública, el manejo de los recursos por concepto de regalías, el establecimiento de las alianzas público - privadas, la propia reestructuración de los entes territoriales conforme a la nueva ley de ordenamiento territorial que dispone la definición de contratos plan en materia de desarrollo de proyectos conjuntos entre diferentes entes territoriales.

El excesivo incremento de las demandas y la valoración en cuantías importantes de las demandas por parte de los estrados tiene en jaque la estabilidad jurídica del estado central y de los entes territoriales descentralizados, regionales y territoriales. A la par, con la insostenible posición asumida por los estrados acerca de la revisión de los juicios luego de sentencia, en particular, de los vinculados a las implicaciones y consecuencias de índole económica de las empresas y que recaen sobre la ya agobiada restricción presupuestal del estado son las principales motivaciones para realizar este escrito. Los exagerados desembolsos y resarcimientos que por petición de los fallos se hacen en ambos casos, indican la poca trascendencia que tiene para el sistema legal y el presupuesto estatal.

La acción de repetición aún no ha logrado pleno alcance por las condiciones y magnitud que representa para el estado revertir las sanciones a las que se hace acreedor en los sujetos y/o instituciones que bajo su tutela o dilación permitieron que se presentara el conjunto de cosas que darían origen a las sanciones impuestas. En este sentido, es importante igualmente señalar que el Estado debe establecer una hoja de ruta clara en cuanto a los pormenores económicos y financieros que deben concebirse a la hora de establecer una acción de repetición que en ocasiones escapa a la capacidad de quien debe refrendar el pago. La acción de repetición solo es el camino para que sea evaluada ampliamente los criterios que originan las sanciones y la forma de recuperarlos de manera tangencial y sustancial al amparo de los hechos que provocaron el desembolso pecuniario del Estado.

El patrón característico de las demandas establecidas en contra del Estado colombiano es que éstas obedecen a procesos altamente calculados por diversos actores de los procesos, que desde las propias instancias judiciales hasta las 
civiles se confabulan y unen para sacar provecho de los vacíos que de forma y de fondo tiene el Estado a la hora de defender su interés y es allí en dicha brecha en donde la demanda termina perdida por la nación y por ende con cargo al presupuesto público. En esta perspectiva, se expresa ampliamente aseveraciones acerca de la existencia de carruseles, grupos o mafias confabuladas para convertir las acciones contra el estado en una importante entrada económica, ya no para los ofendidos por alguna acción de la nación sino para todos quienes en línea con la demanda terminan por orquestar los fallos en contra de la nación ${ }^{5}$.

\section{Estructura institucional y marco legal de la gestión y saneamiento fiscal departamental y municipal}

El panorama ejercido por el marco jurídico y legal proferido por las normas señaladas agudiza a un más las condiciones de los entes territoriales para atender a cuanta función y tarea asigna el gobierno central bajo la dirección del departamental. En este sentido, el cúmulo de responsabilidades que hoy tienen los entes territoriales profundiza aún más la crisis institucional que trajo consigo el desbarajuste provocado por las fórmulas presentadas por los organismos internacionales. En este sentido y conforme a las evaluaciones del Departamento Nacional de Planeación, son muchos los Departamentos que perderían diversos municipios por cuenta de la pérdida de categoría, que si bien no ha hecho carrera en el país, mellaría la capacidad de gasto de los departamentos que tendrían la obligación de entrar a suplir los recursos que por cuenta del proceso de ajuste impuesto se congelarían o disminuirían en los municipios intervenidos y, que de paso, perderían cualquier giro importante por cuenta de la propia perdida categorial.

¿Qué tanto se puede endeudar un agente económico? ¿Es diferente la situación si se trata de una entidad pública, por ejemplo, de un Municipio? A éste, que no es un problema financiero reciente ni único de nuestro país, se le ha añadido un nuevo capítulo con la legislación colombiana del pasado reciente sobre endeudamiento territorial. Sobresale en la Ley 358 -que reglamenta el artículo 364 de la Constitución Nacional- la definición de la capacidad de pago, como el volumen mínimo de ahorro operacional que permite realizar el pago, de manera cumplida, del servicio de la

5 Para ampliar sobre el tema de defensa jurídica del Estado, ver Gutiérrez O., Jahir. (2014). Estructura reglamentaria de la agencia para la defensa jurídica y patrimonial del Estado en Colombia. Revista VIA IURIS, No. 16, Enero-Junio, 2014: 51-69. 
deuda en los años respectivos, permitiendo un remanente para financiar inversiones. Para medir esta situación la Ley establece dos indicadores, el de solvencia, definido como la razón intereses a ahorro operacional2; y el de sostenibilidad, como la razón saldo de la deuda a ingresos corrientes. (Villa et., al, 2005, pág. 150-151).

La llegada de los nuevos mandatarios regionales presentó como antesala la evaluación hecha por los diferentes estamentos de control fiscal y presupuestal, que en suma, identificaron los riesgos a los cuales se está abocando la administración pública territorial (Departamentos y Municipios) en cuanto al desequilibrio en las cuentas entre ingresos, gastos y presupuesto, acompañados por malos manejos, estableciendo a su paso los departamentos y municipios que entrarían en crisis debido a las condiciones fiscales y financieras. Esto a la postre culminarían en la pérdida de categoría territorial y de paso entrar a procesos de intervención directa por parte de los estamentos de orden nacional para establecer de nuevo los criterios fundamentales de los departamentos o municipios o definitivamente dar paso a una revisión más será con respecto a la capacidad y sostenibilidad de los mismos en el tiempo o la posible adhesión a otros territorios

En el plano local, los municipios reflejan un comportamiento más o menos similar al de los gobiernos departamentales. La estructura tributaria local es poco sólida y se caracteriza por un cierto repunte en algunos años para luego registrar una pérdida de participación. Las transferencias siguen siendo el motor que lidera los ingresos de los municipios, lo que permite concluir que sin ellas sería imposible atender los pagos y compromisos, por cierto todavía concentrados en gran medida en los gastos de funcionamiento. (Restrepo \& Álvarez, 2005, pág. 37).

El Departamento de Antioquia, Bajo la tutela del Señor Gobernador, Sergio Fajardo Valderrama, fue notificado al comienzo de esta administración de la posible pérdida de categoría de varios de los municipios del departamento de Antioquia. La razón obvia, inviabilidad financiera y malos manejos presupuestales podrían dejar al departamento con un poco más de la mitad de los municipios de los 125 que lo constituyen. La notificación ha puesto las alertas en toda la administración por lo que puede significar para el gobierno departamental el tener que asumir con cargo a su presupuesto las necesidades y requerimientos de los municipios que amen de la pérdida de categoría tampoco tendría la manera de continuar recibiendo los mismos recursos, terminado ellos abocándose a un ajuste que implicaría la reestructuración de toda su base estamental y por 
ende, más dificultades a la hora de promover crecimiento y desarrollo local. En concordancia con ello, el Departamento Administrativo de Planeación propone en el siguiente Cuadro.

\section{Cuadro 2}

\section{Acciones Para la Viabilidad Fiscal en los Municipios de Antioquia.}

\begin{tabular}{|c|c|}
\hline Vigencias & Acciones \\
\hline $\begin{array}{l}\text { Para los municipios que incumplen } \\
\text { por primera vez: }\end{array}$ & $\begin{array}{l}\text { El Departamento Administrativo de Planeación } \\
\text { de Antioquia, en cumplimiento de la norma, les } \\
\text { acompañará en la construcción y ejecución de su } \\
\text { programa de saneamiento fiscal y financiero. Estos } \\
\text { municipios son: Argelia, Caramanta, Cisneros, } \\
\text { Ebéjico, Ituango, La Pintada, Maceo, Murindó, } \\
\text { Puerto Berrío, San José de la Montaña, San Roque, } \\
\text { Támesis, Valparaíso y Yalí. }\end{array}$ \\
\hline $\begin{array}{l}\text { Para los municipios que acumulan dos } \\
\text { vigencias consecutivas incumpliendo } \\
\text { el indicador de la Ley y } 617 \text { para la } \\
\text { administración central, se recomienda } \\
\text { a la Asamblea Departamental de } \\
\text { Antioquia: }\end{array}$ & $\begin{array}{l}\text { ordenar la adopción de un programa de saneamiento } \\
\text { fiscal y financiero, acompañado por el Departamento } \\
\text { Administrativo de Planeación. En el anexo al } \\
\text { presente informe se encuentra un diagnóstico inicial } \\
\text { y unos lineamientos generales para la construcción } \\
\text { de un programa de saneamiento fiscal. }\end{array}$ \\
\hline $\begin{array}{l}\text { Para los municipios que acumulan } \\
3 \text { o más vigencias consecutivas } \\
\text { incumpliendo el indicador de la Ley } \\
617 \text { para la administración central, y } \\
\text { que por tanto ya poseen un programa de } \\
\text { saneamiento ordenado por la Asamblea } \\
\text { Departamental en noviembre de } 2011:\end{array}$ & $\begin{array}{l}\text { Se recomienda que el Departamento Administrativo } \\
\text { de Planeación haga una evaluación y actualización } \\
\text { de estos programas de saneamiento con la nueva } \\
\text { administración municipal, visto que el programa } \\
\text { anterior tiene pocos meses de formulado lo que } \\
\text { impide evaluar su impacto en el indicador, y fue } \\
\text { adoptado por los alcaldes en la administración } \\
\text { pasada. }\end{array}$ \\
\hline
\end{tabular}

Fuente: Elaborada propia a partir del Informe de Viabilidad Fiscal, Municipios de Antioquia 2011. Departamento Administrativo de Planeación, Gobernación de Antioquia. pág. 19-20.

Las consabidas malas prácticas que constriñen la capacidad de gestión local (la corrupción y la ilegalidad) a cambio de que unos pocos terminen favorecidos con los recursos públicos en detrimento de la inmensa población. La respuesta dada ha dicho escenario ha sido dada a través de que los recursos públicos en cualquiera de sus denominaciones e instancias sean vigilados por distintos observadores y que, con cargo a ello, puedan depurarse bajo control y penalización las prácticas que han debilitado el ejercicio de administrar lo público para el bien común y no para el privado. 
$\mathrm{Al}$ asumir directamente la Gobernación de Antioquia el papel de garante y veedor para que ningún peso de la administración pública termina extraviado o en manos equivocadas, representa más que un eslogan o buen símbolo, el compromiso directo para que la administración pública en cualquiera de sus modalidades extienda ampliamente los criterios de legalidad y transparencia, que paradójicamente terminan mellados desde los puntos de partida y fuente de donde se supone que la administración pública ejerce mayor impacto o beneficio. La educación, la infraestructura, la economía, los temas sociales, la salud entre otros han terminado vulnerados por el acusado ascenso de unas prácticas que desde la clara perspectiva de la Gobernación han adquirido el tamiz de estructurar propias, más no santas de la administración. Por ende, para contrarrestar lo propio han afianzado el interés de luchar contra estas acciones.

El artículo 11 del Decreto 192 de 2001, por el cual se reglamenta parcialmente la Ley 617 de 2000, define el programa de saneamiento fiscal y financiero como "un programa integral, institucional, financiero y administrativo que cubra la entidad territorial y que tenga por objeto restablecer la solidez económica y financiera de la misma mediante la adopción de medidas de reorganización administrativa, racionalización del gastos, restructuración de la deuda, saneamiento de pasivos y fortalecimiento de los ingresos". El Departamento Administrativo de Planeación recomienda, para la formulación de los programas de saneamiento o la actualización de los mismos, seguir el siguiente procedimiento:

1. Priorización: municipios definidos en el presente informe

2. Diagnóstico: se diagnostica la situación actual y se realizan proyecciones financieras

3. Formulación o actualización de Programa de Saneamiento Fiscal: metas y fechas límite

4. Adopción formal del Programa de Saneamiento Fiscal mediante acto administrativo municipal

5. Implementación y seguimiento: se propone la creación de un comité de acompañamiento que haga seguimiento constante para verificar avances.

Esta ruta implica que los programas de saneamiento se formularían posteriores a la realización de un adecuado diagnóstico que permita hacer un programa ajustado a la realidad del municipio con capacidad de tener un impacto positivo. En el anexo se presenta un diagnóstico y unas medidas 
iniciales con base en la información preliminar, información que deberá ser verificada y analizada con posterioridad. En la implementación de los programas de saneamiento es muy valiosa la participación de otros organismos del orden departamental como la Asamblea Departamental, la Contraloría General de Antioquia y el Instituto para el Desarrollo de Antioquia (IDEA). (Departamento Administrativo de Planeación, Gobernación de Antioquia, 2011, pág. 20).

La priorización en el desempeño fiscal y financiero de varios de los municipios identificados por la gobernación de Antioquia establece un claro marco de convergencia a la hora de comprender la trascendencia que tiene dicha focalización. Tras la identificación de los municipios, se establecen los criterios transversales para que los municipios que aún no tienen dificultades, continúen haciendo esfuerzos tributarios y presupuestales. Dicha premisa, es la que hoy conduce a la Gobernación de Antioquia a establecer los criterios y lineamientos para que los Municipios priorizados (véase cuadro 2) definan el marco del desempeño fiscal y la conducta financiera sobre la cual estarían dispuestos a establecer acuerdos para lograr salir de las dificultades indicadas. El propósito planteado por la Gobernación implica un ajuste directo a los Municipios implicados. De lo contrario, la ley establecida (Ley 617 de 2000), dispone las directrices que deben atenderse cuando un municipio no alcanza niveles mínimos de estabilidad, epicentro que se traduce en la pérdida de categoría o en el detrimento de las condiciones de habitabilidad territorial municipal.

La disposición de guías magistrales y el interés por establecer líneas de trabajo para mejorar las condiciones financieras, fiscales y de gastos en los municipios, ha pasado de la orientación propia de los organismos de control, fiscalización y vigilancia a un cometido de carácter departamental que tiene como epicentro la gestión actual. Por ende, busca que cada municipio de Antioquia en situación de debilidad institucional con cargo a la situación de malos manejos pueda salir adelante o por lo menos recuperar las condiciones básicas para su viabilidad, pero esto se logra, en la medida en que la articulación de las propuestas del orden nacional y departamental tengan asiento en las discusiones y propuestas que con cargo a ello pudiesen desarrollar las administraciones locales de manera directa, pero con supervisión departamental, en cuyo marco se extiende la presente propuesta de intervenir en el fortalecimiento municipal. 


\section{Programación financiera y fiscal de los entes municipales del departamento de Antioquia}

El ubicar la propuesta en la programación fiscal y financiera a la vez que, en la planeación y desarrollo de los municipios conforme al acompañamiento y fortalecimiento de los municipios en cuanto al manejo de sus ingresos, la gestión financiera y fiscal, atizados ambos por la definición de programas particulares de saneamiento financiero y fiscal de los municipios, destaca el interés de la gobernación departamental en Antioquia de conducir a los municipios al otro lado de su situación. La entereza mostrada al establecer con prioridad dicho trabajo implica una preocupación plena, pero también un profundo interés por establecer para los entes territoriales, más que un puente, un escenario de trabajo mancomunado en el que las circunstancias de los municipios también son de interés del departamento que, si bien puede tener interesantes datos en dicha materia, la sola flaqueza de los municipios a saber, expone cualquier solidez particular.

El connato de repercusiones aún no ha sido cuantificado o evaluado respecto a los elementos que debe asumir la Gobernación y los Municipios de manera conjunta y directa cuando uno de estos últimos termina por perder la categoría o pasar del nivel municipal a otras instancias por definición territorial enmarcadas en la ley. El vínculo Estado-gobierno central de manera gerencial, ya se vive en lo que respecta al vínculo Estado - descentralizado en lo departamental y municipal, en donde en cada uno de ellos adopta la figura de gran gerente o administrador, con el ánimo de procurar la mayor eficiencia.

Entre los desafíos fiscales que enfrenta el gobierno colombiano, el debate sobre la "inflexibilidad" del presupuesto tiene particular importancia. En efecto, el gobierno tiene un escaso margen de maniobra al preparar el presupuesto, dado que un alto porcentaje de los gastos que debe hacer cada año está predeterminado. Un numeroso conjunto de leyes y artículos constitucionales, determina hoy en día la manera como el gobierno debe asignar sus ingresos. Este fenómeno, además de comprometer la capacidad de los representantes elegidos para ejecutar sus planes de gobierno, la inflexibilidad del presupuesto puede arriesgar la estabilidad macroeconómica, por cuanto dificulta los ajustes en situaciones fiscales deficitarias. (Rentería \& Echeverry, 2006, pág. 33). 
En cabeza de las administraciones departamentales, está expuesta la probabilidad para que los Municipios salgan de las actuales circunstancias en que se encuentran o de paso estén encaminados a plantear procesos que contribuyan a su reestructuración o recomposición para continuar denotando el carácter municipal o en su defecto allanar otros caminos para que puedan recuperarse de tajo. El escenario planteado para lograr dicho propósito está dirigido al desarrollo de una serie de actividades programadas a través de la integración de diferentes esfuerzos, entre los que se cuenta, la participación de estamentos encargados de darle trámite a la propuesta. A su vez que, a la realización de diferentes actividades de capacitación, cultura, educación y formación en temas inherentes al fortalecimiento de los ingresos y el buen manejo de los gastos vinculados con cada nivel municipal.

El destino que tomen las finanzas municipales aborda directamente la dirección que con respecto al propio elemento pueda materializar la gobernación de Antioquia. Lejos de cualquier intención coyuntural, la probabilidad de que puedan materializarse los distintos esfuerzos en materia de gastos e ingresos está sujeta a las condiciones estamentales e institucionales que asuman cada uno de los municipios elegidos para ser intervenidos. A la postre, no es solo la intención de abordar un tema que continúa sobresaliendo en la gestión pública. La carrera y mella que ha creado está situación desvirtúa cualquier intención de mejorar las condiciones fiscales y financieras del propio departamento, en cuyo haber descansa el papel de equilibrar las finanzas conforme a las fuentes de financiación directa o de las que pueda disponer de manera gerencial.

Diversos mecanismos han sido utilizados para que las cuentas en la estructura fiscal y financiera de los municipios colombianos concuerden. Bajo leyes y decretos a nivel nacional y de origen externo algunos han sido creados para el manejo de las cuentas municipales. Sin embargo, pese a los esfuerzos éstos no han conducido al mejoramiento la gestión financiera municipal. No se trata sólo de vigilancia, dirección, ejecución, evaluación, seguimiento y control, también es fundamental conocer la capacidad óptima del manejo fiscal y de financiariedad desde la perspectiva internacional, nacional, departamental, regional y local que está en condiciones de afrontar. Por ende, desde la perspectiva de ente económico es necesario analizar las posibilidades que tienen los municipios en la gestión de recursos propios, de regalías, de transferencias, y de cooperación internacional en Colombia. 
El seguimiento y evaluación de la regla fiscal se debe realizar mediante criterios de independencia, calidad técnica, credibilidad, transparencia y oportunidad. En razón a que se debe preservar el principio de independencia y objetividad en la evaluación del cumplimiento de las metas fiscales, se sugiere la creación de un Comité Externo de Evaluación de la Regla Fiscal (Ceerf), el cual estaría conformado por tres integrantes con las más altas calidades profesionales y con un amplio conocimiento del tema macroeconómico y fiscal. Los tres integrantes del Ceerf serían nombrados en conjunto por el Gerente General del Banco de la República, el director del Departamento Nacional de Planeación y el Ministro de Hacienda y Crédito Público. (Comité técnico interinstitucional, 2010, pág. 48).

La forma como se hace administración pública municipal en Colombia invita a reflexionar sobre ella a manera de diagnóstico, análisis, consideraciones y disertaciones en cuanto a la importancia actual de la gerencia pública para permitir obtener ganancias importantes y de decisiones para quienes están al frente de las administraciones municipales en el país. De manera latente, existe la preocupación del gobierno central colombiano ante el grado de respuesta que han dado los municipios para salir de las difíciles condiciones fiscales y de viabilidad económica y presupuestal en que se encuentran, más que por las condiciones o exigencias de ley, por los elementos que advierten que debe prevalecer un orden para que los municipios no vuelvan a caer en estado de mora o incapacidad de pago de sus acreencias, o en un proceso de inviabilidad financiera.

De otro lado insiste el Gobierno Departamental, en que los municipios deben procurar la creación de otros o nuevos recursos para su sostenibilidad, petición que se ha vuelto condición por cuanto la relación económica entre este y los entes territoriales está disminuyendo, y tiende en el tiempo a reducirse. De ahí que, muchos municipios y departamentos están incursionando en diferentes campos como los proyectos de infraestructura o inversiones para tratar de tener algún flujo de liquidez.

En cuanto al futuro de las finanzas territoriales y la capacidad de financiación que esta pueda generar, los municipios deberán en adelante mejorar las posibilidades de acceso a recursos, convirtiéndose prácticamente en expertos en dicha materia con el propósito de consolidar la tan anhelada autonomía económica y financiera, dado que tras de ella más que un juego de relaciones de flujos de ingresos y gastos, lo que está en juego es la capacidad de gestionar 
futura de los mismos, y la mejor manera de mostrarlo es a través de la obtención de recursos. En síntesis, se pretende analizar las condiciones idóneas con las que debe contar un municipio para estructurar su propia autonomía contando más con la capacidad de gestión propia que con las fuentes de financiación tradicionales o cuyo peso son de más tradición como las de origen estatal, dejando por primera vez para el caso colombiano hablar realmente de gestión pública territorial con miras a la obtención de fuentes de ingresos y recursos que permitan a los municipios ser autónomos en sus decisiones o por lo menos en cuanto al uso y disposición de los recursos precisamente conforme a los esfuerzos hechos por estos en la materia. (Véase cuadro 3)

\section{Cuadro 3}

\section{Rendición de Cuentas en los Modelos de Gestión Pública}

\begin{tabular}{|c|c|c|c|c|c|}
\hline $\begin{array}{l}\text { Características } \\
\text { Modelos de } \\
\text { gestión }\end{array}$ & Objeto & $\begin{array}{l}\text { Sujeto } \\
\text { receptor de la } \\
\text { rendición de } \\
\text { cuentas }\end{array}$ & $\begin{array}{l}\text { Sujeto } \\
\text { que rinde } \\
\text { cuentas }\end{array}$ & $\begin{array}{l}\text { Medición de } \\
\text { rendición de } \\
\text { cuentas }\end{array}$ & $\begin{array}{l}\text { Propósito de } \\
\text { la rendición de } \\
\text { cuentas }\end{array}$ \\
\hline Weberiano & $\begin{array}{l}\text { Demostración } \\
\text { del } \\
\text { cumplimiento } \\
\text { de políticas } \\
\text { y procesos } \\
\text { legalmente } \\
\text { establecidos }\end{array}$ & $\begin{array}{l}\text { Instancias } \\
\text { superiores } \\
\text { legalmente } \\
\text { establecidas. }\end{array}$ & $\begin{array}{l}\text { Distintos } \\
\text { niveles de } \\
\text { dirección. }\end{array}$ & $\begin{array}{l}\text { Informes } \\
\text { confidenciales }\end{array}$ & $\begin{array}{l}\text { Control del } \\
\text { cumplimiento } \\
\text { de políticas } \\
\text { y procesos } \\
\text { formalmente } \\
\text { establecidos. }\end{array}$ \\
\hline $\begin{array}{l}\text { Burocrático } \\
\text { Populista }\end{array}$ & $\begin{array}{l}\text { Demostración } \\
\text { de obras } \\
\text { ejecutadas, } \\
\text { inversiones y } \\
\text { gasto público }\end{array}$ & $\begin{array}{l}\text { Instancias } \\
\text { superiores extra } \\
\text { - organizativas } \\
\text { legalmente } \\
\text { establecidas }\end{array}$ & $\begin{array}{l}\text { Altos niveles } \\
\text { de dirección. }\end{array}$ & $\begin{array}{l}\text { Informes } \\
\text { anuales, } \\
\text { formalmente } \\
\text { públicos en } \\
\text { la práctica } \\
\text { restringida. }\end{array}$ & $\begin{array}{l}\text { Legitimación del } \\
\text { gasto público. } \\
\text { Cumplimiento } \\
\text { de Rendición } \\
\text { de Cuentas } \\
\text { formalmente } \\
\text { establecidos. }\end{array}$ \\
\hline Tecnocrático & $\begin{array}{l}\text { Demostración } \\
\text { del } \\
\text { cumplimiento } \\
\text { de metas } \\
\text { programadas }\end{array}$ & $\begin{array}{l}\text { Instancias } \\
\text { de dirección } \\
\text { superiores } \\
\text { internas y } \\
\text { externas de la } \\
\text { organización. } \\
\text { Sectores } \\
\text { económicos. }\end{array}$ & $\begin{array}{l}\text { Distintos } \\
\text { niveles de } \\
\text { dirección. }\end{array}$ & $\begin{array}{l}\text { Informes } \\
\text { sistemáticos } \\
\text { confidenciales. }\end{array}$ & $\begin{array}{l}\text { Control del } \\
\text { cumplimiento } \\
\text { de metas } \\
\text { programadas. } \\
\text { Legitimación de } \\
\text { la racionalidad } \\
\text { economicista. }\end{array}$ \\
\hline
\end{tabular}




\begin{tabular}{|l|l|l|l|l|l|}
\hline $\begin{array}{l}\text { Nueva } \\
\text { Gerencia } \\
\text { Pública } \\
\text { (Propuestas) }\end{array}$ & $\begin{array}{l}\text { Demostración } \\
\text { del }\end{array}$ & $\begin{array}{l}\text { Instancias } \\
\text { de dirección } \\
\text { cumplimiento } \\
\text { de metas } \\
\text { internas y } \\
\text { externas } \\
\text { Programas. } \\
\text { superiores }\end{array}$ & $\begin{array}{l}\text { Distintos } \\
\text { niveles de } \\
\text { dirección. }\end{array}$ & $\begin{array}{l}\text { Medios de } \\
\text { difusión } \\
\text { masivos. }\end{array}$ & $\begin{array}{l}\text { Control del } \\
\text { cumplimiento } \\
\text { de metas } \\
\text { yrogramadas, }\end{array}$ \\
& efectividad \\
en el usuario. & $\begin{array}{l}\text { lestablecidas } \\
\text { ciudadano- } \\
\text { usuario. }\end{array}$ & & & $\begin{array}{l}\text { y efectividad } \\
\text { en el usuario. } \\
\text { Legitimación de } \\
\text { la racionalidad } \\
\text { del mercado. }\end{array}$ \\
\hline
\end{tabular}

Fuente: Ochoa, H., \& Montes de Oca, Y. (2004). Pág.470.

La disposición planteada por el orden regional, si bien está prescrita de manera legal y normativa a su vez que propositiva, está sujeta a la capacidad de interacción, gestión y respuesta que pueda dar el orden regional para el efecto de los requerimientos que exija el acompañamiento entre las dos instancias. En este sentido, es claro que a medida que el proceso de intervención en materia del acompañamiento avance, se requerirán además de planteamientos, iniciativas y propuestas que exigen de tajo el otorgamiento de recursos de naturaleza pública, estrategias de salvamento o mecanismos que apunten a recuperar los fundamentales y parámetros que identifican el quehacer en materia de ingresos, gastos y desembolso de recursos para ejecución.

La planificación financiera es un instrumento por medio del cual se determinan los recursos y las mejores opciones para la gestión que emprendió el Gobierno Departamental a principios de 2012 mediante la ejecución del plan de desarrollo Antioquia La Más Educada. Esta planificación se hace con base en las operaciones efectivas de caja, partiendo de la situación actual, lo que permitirá visualizar el comportamiento en el corto, mediano y largo plazo del estado de las finanzas del ente territorial; en el proceso se considera el comportamiento de los ingresos, los egresos, la generación de ahorro o déficit y las formas de financiación, dentro de las normas legales vigentes. (Ordenanza No 14 de 2014, pág. 273-274).

El curso que pueda tomar la intervención con cada Municipio depende de la realidad que se pretenda revertir en ellos. Las condiciones o elementos explicativos son disimiles, y como tal, cualquier acercamiento debe provocar un espacio de revisión del contexto al cual está abocado el Municipio de continuar por cuenta propia, tratando de ilustrar un marco de compromisos en materia fiscal con observancia de los organismos respectivos o dar el paso para reglar 
la estructura fiscal y financiera conforme a una política integral de ajuste que cuente con la cercanía, interés y disposición de la administración departamental. Es el paso importante, el poder orientar mancomunadamente un trabajo en donde pueda pasarse al otro lado de la crisis. Sin una manifestación plena por parte de los municipios antioqueños de principio a fin y conforme a un cúmulo de criterios a los que haya lugar, entre acuerdos y puntos de diferencia, el acercamiento a cada uno de ellos y la reciprocidad del trabajo se encuentra estimado en la capacidad de internalizar los hechos que han hecho débil la actual situación fiscal y financiera de los Municipios. De lo contrario, el solo respaldo gubernamental no es suficiente, por cuanto, se requiere una posición expresa del ente en cuanto a su disposición de superar sus limitantes que, en el peor de los casos, conlleva a la pérdida de la categoría y, por ende, de los recursos escasos.

El acierto de la iniciativa radica en la posibilidad de materializar los ejercicios de acompañamiento en materia de planeación financiera y gestión de recursos públicos en aras del fortalecimiento de ingresos y gastos. La secuencia lógica del proceso radica en orientar los destinos de los Municipios que se encuentran en situación críticas en aras de facultar a los entes territoriales para que tomen sus propias decisiones. Además, coordinen conforme a sus posibilidades los instrumentos y mecanismos para en rutar el quehacer de la gestión pública hacia la consecución de resultados tanto en rendición de cuentas como en el mejoramiento de los indicadores que los pueden impulsar hacia mejores posibilidades, aprovechando las complementariedades que podrían obtenerse con respecto a los proyectos de infraestructura, hidroeléctrica y Mineros entre otros.

\section{CONCLUSIONES}

El resultado de la iniciativa municipal está sujeta a la obtención de los siguientes elementos de trabajo: 1. Una propuesta de reestructuración administrativa, contable y financiera para mejorar o sostener la categoría municipal; 2. Una ilustración fiscal y presupuestal, afincada en la consideración de nuevas contribuciones, impuestos y rentas por cada grupo de categoría municipal, y 3. Un instrumento de gestión financiera municipal, que sirva de elemento, fundamento y manual redactor para la sostenibilidad fiscal en el largo plazo. Es importante que los Municipios trasciendan del componente político 
al económico, que en definitiva determina la categoría y gestión municipal y más aún cuando la evaluación sobre dichos componentes está por encima de cualquier interés individual, sesgo político o partidista en la materia, que no ha tomado con impronta estas prerrogativas.

La posibilidad de conformar otras denominaciones o núcleos territoriales hace parte de la estela de propuestas que representan las iniciativas que podrían solventar las prerrogativas enfocadas en la pérdida de categoría municipal. Salvar a la categoría reconfigurando la estructura municipal en cuanto a la composición de los cuerpos de concejos, gabinetes o empleados constituye un marco de criterios que aún no ha sido estimado completamente por los entes territoriales. El poder auspiciar la creación de secretarias conjuntas intermunicipales, bajo intereses comunes, o incluso elevar la calidad y condiciones de la administración pública local hacia estructuras de más carácter regional y territorial aún hacen mella en las aletargadas condiciones políticas que aún consideran que la estructura municipal es intocable, incluso por encima de la ley.

El centro del aporte de este análisis está contemplado para dar instrumentos de trabajo a los entes territoriales municipales en Antioquia que, en cualquiera de los casos, requiera de referencias puntuales para acoger, permanecer o sobrellevar a cuestas las exigencias que se plantean en la legislación. Asimismo, el de poder entregar esquemas de evaluación financiera y presupuestal que atiendan en cualquiera de los casos, de los Municipios que mejoren o de los que deben hacer parte de una nueva forma territorial, la revisión completa sobre dichos temas. A su vez, que el de indicar las bondades de acoger este tipo de movilidades legislativas en materia económica y territorial como una oportunidad que puede traer más resultados positivos que negativos a los entes territoriales en cuanto a la concentración de esfuerzos y de más oportunidades a la población en cualquier circunstancia.

\section{REFERENCIAS}

(1) Asamblea Departamental de Antioquia. Ordenanza No 14 de 2014: https://colaboracion. dnp.gov.co/CDT/Desarrollo\%20Territorial/Portal\%20Territorial/KIT-OT/Plan-de-Desarrollo-Antioquia-2012-2015.pdf 
(2) Comité Técnico Interinstitucional. (2010). Regla fiscal para Colombia. Banco de la República. Ministerio de Hacienda y Crédito Público. Departamento Nacional de Planeación. Bogotá, D. C., 7 de julio de 2010. 1-135.

(3) Congreso de la República. Constitución Política de Colombia de 1991. Edición 2016. Temis. Bogotá D.C.

(4) Congreso de la República. Ley 1551 de 2012. Bogotá. Diario Oficial. 48.483

(5) Congreso de la República. Ley 1454 de 2011. Bogotá. Diario Oficial. 48.115

(6) Congreso de la República. Ley 1450 de 2011. Bogotá. Diario Oficial. 48.102

(7) Congreso de la República. Ley 1150 de 2007. Bogotá. Diario Oficial. 46.691

(8) Congreso de la República. Ley 819 de 2003. Bogotá. Diario Oficial. 45.243

(9) Congreso de la República. Ley 795 de 2003. Bogotá. Diario Oficial. 45.064

(10) Congreso de la República. Ley 715 de 2001. Bogotá. Diario Oficial. 44.654

(11) Congreso de la República. Ley 617 de 2000. Bogotá. Diario Oficial. 44.188

(12) Congreso de la República. Ley 358 de 1997. Bogotá. Diario Oficial. 42.973

(13) Departamento Administrativo de Planeación, Gobernación de Antioquia (2011). Informe de Viabilidad Fiscal, Municipios de Antioquia. Vigencia 2011.

(14) Dirección de Desarrollo Territorial Sostenible. (2009). Fuentes de financiación del gasto de inversión territorial. Departamento Nacional de Planeación.

(15) Dirección de Desarrollo Territorial Sostenible. (2005). Capacidad fiscal de los gobiernos territoriales colombianos. Departamento Nacional de Planeación. 1-57.

(16) Herrera, A. (2003). Régimen presupuestal de los municipios en Colombia. Revista de derecho, No 19, Enero-Junio, 19-51.

(17) Ministerio de Hacienda y Crédito Público (2011). Dirección General del Presupuesto Público Nacional. Aspectos generales del proceso presupuestal colombiano. - $2 \mathrm{a}$ ed. - Bogotá: 520 p.

(18) Ochoa, H., \& Montes de Oca, Y. (2004). Rendición de cuentas en la Gestión Pública: Reflexiones teóricas. Revista Venezolana de Gerencia (RVG) año 9. No 27: Julio - Septiembre: $455-472$. 
(19) Rentería, C., \& Echeverry, J., C. (2006). Presupuestar en Colombia: buscando la gobernabilidad fiscal a través del presupuesto. Instituto Latinoamericano y del Caribe de Planificación Económica y Social - ILPES S E R I E Gestión Pública 61: 1-51.

(20) Restrepo, Q., G. \& Álvarez, V., D. (2005). Ley 617 de 2000 y su impacto fiscal territorial. Ensayos sobre economía regional. Centro Regional de Estudios Económicos CREE Medellín:1-56.

(21) Villa, G., A., Escobar, S., H., E., Camargo, M., R., (2005). Estudio sobre la sostenibilidad de la deuda del municipio de Medellín. Revista Ciencias Estratégicas, Vol. 13, No 14, Julio-Diciembre:149-162.

(22) Zapata, J., G., Acosta, O., L., \& González, A. (2001). Evaluación de la descentralización municipal en Colombia: ¿Se consolidó la sostenibilidad fiscal de los municipios colombianos durante los años noventa? (Documento elaborado por la Dirección de Desarrollo Territorial del DNP). Documento 165: 1-86.

(23) Zuluaga, C., (s.f). Sostenibilidad de las Finanzas Públicas Territoriales. Ministerio de Hacienda y Crédito Público: https://www.cepal.org/ilpes/noticias/paginas/5/22145/Zuluaga. pdf 